\title{
SECTION 4: POST-PROSTAT COMPLICATIONS-REVIEW
}

\section{Posterior urethral complications of radical prostatectomy}

\author{
Michael Coburn, MD, FACS \\ Professor and Chairman, Scott Department of Urology, Baylor College of Medicine, and Chief of Urology, Ben Taub General Hospital, Houston, TX
}

Cite as: Can Urol Assoc J 2013;7(9-10):S192-4. htrp://dx.doi.org/10.5489/cuaj.1622 Published online October 7, 2013.

\section{Abstract}

The incidence of vesicourethral anastomotic stenosis following radical prostatectomy has fallen over the past two decades, but it remains a relatively common complication of this procedure. Options for management include endoscopic and surgical approaches. These options are briefly discussed in this review and a management algorithm is proposed.

$\mathrm{R}$ adical prostatectomy (RP) may lead to several potential postsurgical complications. This brief summary provides an overview of one of the most common: vesicourethral anastomotic stenosis (VUAS). The epidemiology is briefly discussed and the options for management presented. These options are summarized in the algorithm in Figure $1{ }^{1}$

\section{Epidemiology}

Although VUAS remains a common potential complication of $\mathrm{RP}$, the incidence has dramatically fallen over time. A study by Wennberg et al, published in 1993, showed that the stricture rate post-RP was approximately $20 \% .^{2}$ More recently, a large retrospective analysis of RP patients at the Memorial Sloan-Kettering Cancer Center ( $n=4,592$ patients undergoing RP), published in 2010 , showed that the incidence of VUAS among post-RP patients had fallen to $2.8 \% .^{3}$

\section{Management options}

There are a number of different options available for the management of VUAS. Essentially, they are to dilate, incise/resect (with our without injection), insert a stent, redo the anastomosis or divert. The evidence base for each of these interventions is relatively small, and the success rates in the studies that are available are variable, ranging from $47 \%$ to $100 \%$ (Table 1 ). ${ }^{1}$ The variability in success rates is likely due to the variability in the properties of the stenoses themselves rather than the techniques. There is no clear evidence to support the use of one type of technology over another. The approximate percentage of patients who can be considered to be recalcitrant (i.e., failed at least one dilation and incision, resection) is 1 to $2 \%$. The recalcitrance may be due to ischemia at anastomotic site and/or anastomotic dehiscence in the early postoperative period (hematoma, technical).

\section{Dilation}

Dilation is an attractive option for those patients who are reluctant to undergo more invasive surgical interventions and whose strictures allow access of a dilating device. There are a number of such devices available for use in this regard, both for office use and for patients to self-dilate as needed at home. In terms of the type of dilator used, radial dilation (such as with the use of an inflatable urethra-specific balloon catheter) may be preferred over longitudinal dilation, as it avoids the possibility of longitudinal mucosal shearing, with submucosal hemorrhage, hematoma and/or inflammation. This method would also have a lower risk of injury to adjacent normal tissues proximal or distal to the stricture. The level of discomfort with radial dilation is also lower than with semirigid sequential dilation. Finally, radial dilation may allow patient to become self-sufficient with a minimally traumatic procedure.

\section{Stenting}

Although the UroLume stent (manufactured by American Medical Systems) will no longer be available in Canada, it is important for urologists to be aware of this technique, as it has been used in this country in the past and is still in use in many parts of the world, including the United States. The UroLume is a woven, selfexpanding, permanent urethral stent made from a non-magnetic, metallic alloy. It is expandable to $14 \mathrm{~mm}$ (42 French) and is available in lengths of $1.5 \mathrm{~cm}$ to $3.0 \mathrm{~cm}$ (in $0.5 \mathrm{~cm}$ increments). There are some significant drawbacks to this technique, including a tendency for the stent to displace distally with deployment. It should not be seen as a simple, permanent solution, but one that requires regular monitoring and maintenance. Patients with these stents in place should undergo routine endoscopic reassessment, at least 


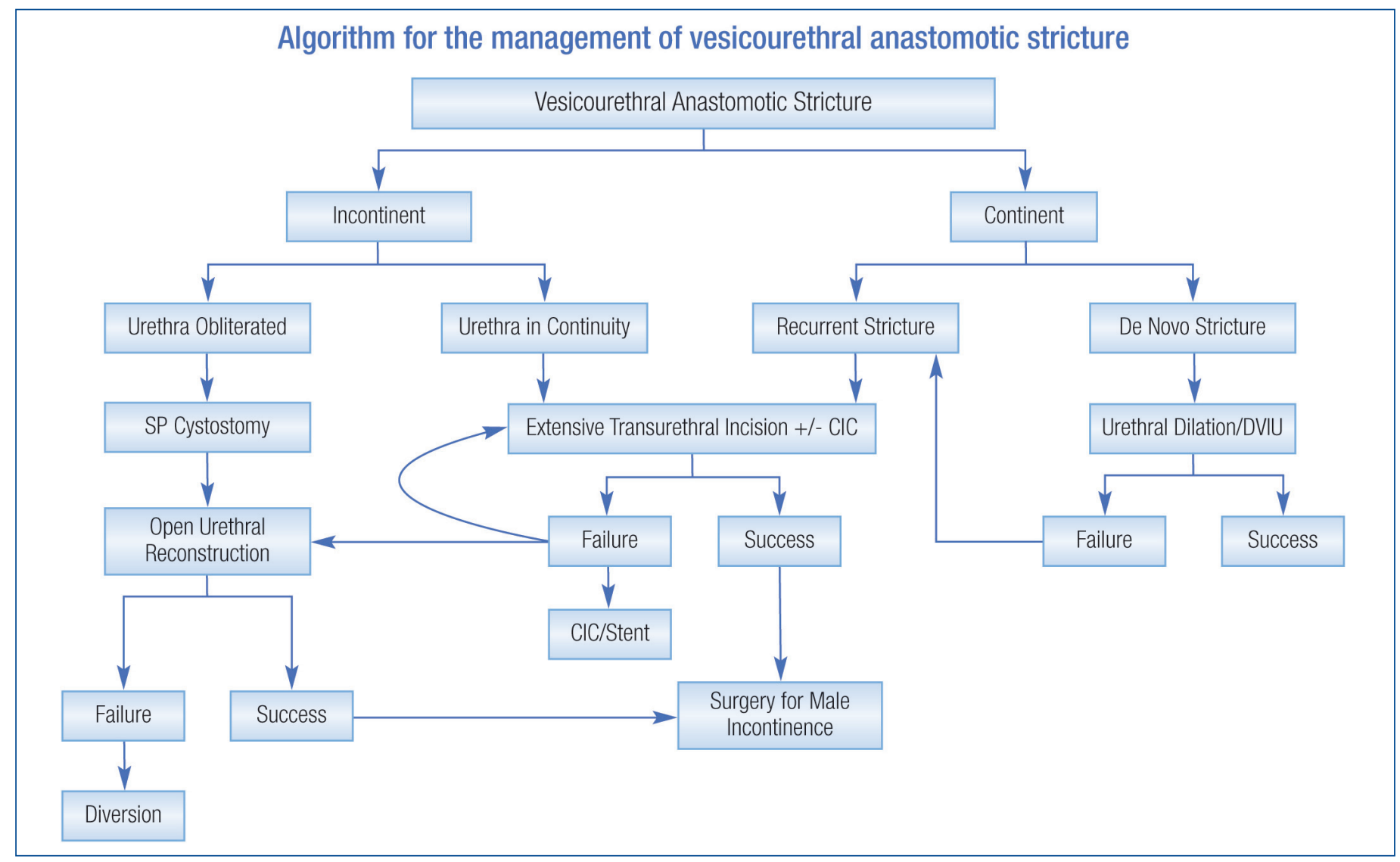

Fig. 1. Algorithm for the management vesicourethral anastomotic stricture.

every year and any time there are signs or symptoms suggesting complications (e.g., abnormal urinalysis, gross hematuria, urinary tract infection, irritative or obstructive symptoms, stone passage).

\section{Novel approaches}

The injection of bioactive agents into the incision site has been explored as a method of improving outcomes and preventing restenosis. Botulinum toxin is one such agent that has been used in a small number of patients in an effort to prevent scars from forming. ${ }^{4}$ There has also been a report of successful outcomes in a retrospective review of 18 cases in which recurrent bladder neck contractures were managed with urethrotomy and intralesional injection of mitomycin C. ${ }^{5}$ Further study is needed for these interventions.

\section{Surgical approaches}

Should endoscopic approaches prove insufficient, the surgical options available to address stenoses include reconstruction and diversion. Reconstructive surgery consists of a redo anastomosis. Standard surgical approach, barring anatomic considerations in the individual patients that would preclude such an approach, is from above, retropubically, with perineal incision reserved for those cases where it is necessary to mobilize the anterior urethra to gain sufficient access and length. This can involve full resection of the ischemic tissue and a full new anastomosis, or a Y-V-plasty at the anastomotic site. There are many potential complications of this type of surgery, and it may not even be possible to complete the operation as planned. As such, preoperative counseling with the patients needs to include management of expectations and a frank discussion of the possible complications.

If the patient is not a suitable candidate for reconstruction (or if such an approach has failed), the other surgical option is a permanent diversion (e.g., permanent suprapubic cystostomy, catheterizable stoma to the bladder). Many patients are content to live with this solution if it means avoiding further invasive abdominal surgery(ies).

\section{Conclusions}

The type of intervention selected for the management of VUAS will depend on the individual patients' symptoms, degree of bother, and anatomical considerations. Endoscopic approaches can be successful for many patients and are preferred over surgical options whenever possible. When considering surgery, one should ensure that the patient is fully aware of the potential complications and the options available. While diversion has been typically reserved for cases in which reconstruction is not possible or has failed, one should consider presenting it as a surgical option upfront after failure of endoscopic approaches. 
Coburn

\begin{tabular}{lccc}
\hline \multicolumn{4}{c}{ Table 1. Options for the endoscopic treatment of VUAS } \\
\hline Treatment & Year & N & Success (\%) \\
\hline DVIU & 1990 & 18 & 62 \\
& 1996 & 17 & 88 \\
HO:YAG laser & 2000 & 52 & 58 \\
& 2005 & 3 & 100 \\
Dilation & 2005 & 10 & 100 \\
& 1994 & 27 & 59 \\
& 2006 & 43 & 100 \\
Urolume & 1995 & 80 & 38 \\
& 1999 & 2 & 100 \\
& 2001 & 1 & 100 \\
TUR & 2002 & 9 & 89 \\
Endourethral & 1998 & 24 & 100 \\
Brachytherapy & 2004 & 15 & 47 \\
Endourethroplasty & 1996 & 2 & 100 \\
& 2010 & 11 & 55 \\
\hline
\end{tabular}

DVIU: Direct visual internal urethrotomy; TUR: transurethral resection

Competing interests: This article is part of a CUAJ supplement sponsored by Astellas Pharma Canada, Inc.

\section{References}

1. Herschorn $S$, Elliott $S$, Coburn $M$, et al. Posterior urethral stenosis after treatment for prostate cancer. Urethral Strictures, An International Consultation on Urethral Strictures. G. Jordan, C. Chapple, and C. Heyns. Societe Internationale d'Urologie, Montreal, Canada, 2012, pp. 197-240.

2. Fowler FJ Jr, Barry MJ, Lu-Yao G, et al. Patient-reported complications and follow-up treatment after radical prostatectomy. The National Medicare Experience (1988-1990) (updated June 1993). Urology 1993;42:622-9. http://dx.doi.org/10.1016/0090-4295(93)90524-E

3. Rabbani F, Yunis $L H$, Pinochet $R$, et al. Comprehensive standardized report of complications of retropubic and laparoscopic radical prostatectomy. Eur Urol 2010;57:371-86. http://dx.doi.org/10.1016/i. eururo.2009.11.034

4. Khera M, Boone TB, Smith CP. Botulinum toxin type A: a novel approach to the treatment of recurrent urethral strictures. J Urol 2004;172:574-5. hitr://dx.doi.org/10.1097/01.ju.0000130652.27541.22

5. Vanni AJ, Zinman LN, Buckley JC. Radial urethrotomy and intralesional mitomycin C for the management of recurrent bladder neck contractures. J Urol 2011;186:156-60. hittp://dx.doi.org/10.1016/i. juro.2011.03.019

Correspondence: Dr. Michael Coburn, Baylor Clinic, Adult Care and Services, 6620 Main St., Suite 1325, Houston, TX 77030; mcoburn@bcm.edu 